Brit. F. industr. Med., 1968, 25, 52.

\title{
The History of the Statutory Control of Mercury Poisoning in Great Britain ${ }^{1}$
}

\author{
W. R. LEE \\ From the Department of Occupational Health, University of Manchester
}

\begin{abstract}
'Notification is only useful as the prelude to inquiry and recommendations, and without such development, is nothing more than a cog in the wheel of statistics which resolves annually but gets nowhere.'

Sir Frank Tillyard (1948)
\end{abstract}

\section{Early Developments}

During the first 50 years, from the start of the factory inspectorate in 1833, the inspectors' reports contained only scattered reference to ill health. In the Chief Inspector's Report for I879 was a section headed 'Occupations injurious to health', although mercury was not among the topics discussed.

Under the Factory and Workshop Act of 1878 , young persons were prohibited from employment in certain industries, one of which was the silvering of mirrors by the mercurial process. This was a rather belated piece of legislation, as the trade was, by then, rapidly dying out (Legge, 1902). Evidence continued to accumulate on the harm of certain trades and, more especially, on the magnitude of the harm being inflicted on workers in Great Britain. This knowledge was incorporated in the 1895 Factory and Workshop Act, which introduced for the first time the requirement for the notification of four industrial diseases-lead, arsenic and phosphorus poisonings, and anthrax. Thus the principle of notification had been established.

The acknowledgement of harm accruing from work was met by the Victorians in characteristic fashion. They set up a committee, the Home Office Dangerous Trades Committee (I898), to examine a long list of industries and processes 'and to report what, if any, special rules should be made under section 8 of the Factory and Workshop Act of 1891 , for the protection of the persons employed in these industries'. Surprisingly, the only mercury hazard investigated by this committee was from the Blake shoe sole stitching machine (Fig. I). They investigated

${ }^{1}$ Based on a paper read at a Symposium on Mercury Toxicity held at Queen's College, Dundee, in October 1966. two deaths, alleged to have been caused by work at this machine but attributed one to excessive drinking and the other to tuberculosis.

\section{The Decision for Notification}

But the factory inspectors were not waiting on the reports of committees; in the Chief Inspector of Factories Report for 1897 one inspector reported on a worker in a scientific instrument factory using cold metallic mercury. He commented: 'She says she left her employment owing to the injury to her health. The firm, however, say they had to discharge her owing to her spreading injurious reports about them.' His report continues: 'Owing to this being the only place in this district in which such a process is carried on, and this, until last May, the only woman so employed, I have been unable to carry these investigations further.' The occupation of this woman, as a scientific instrument maker, is interesting, for during the ensuing 70 years the trade has supplied a steady stream of notified cases of mercury poisoning, including three out of the six cases notified in 1964 (Chief Inspector's Report, 1965).

Within the Factory Department itself, Legge, very soon after his appointment as the first Medical Inspector of Factories in 1898, made arrangements that the Registrar General should notify him of all deaths attributed to mercury (and certain other causes) (Chief Inspector's Report, 1899). This first and somewhat elementary control system is illustrated in Figure 2. At the same time evidence collected by the inspectors in the factories was being carefully studied. The Principal Lady Inspector wrote to the Chief Inspector in September 1898 (Anderson, 1898a) that 'various cases of this form of 


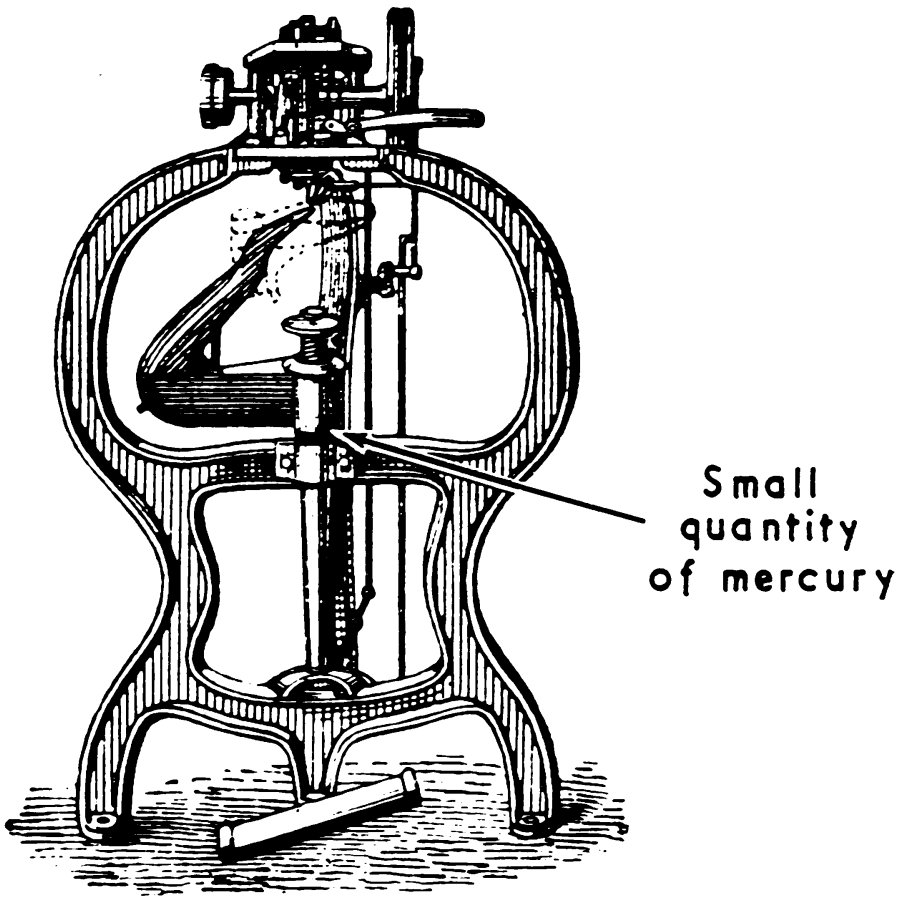

FIG. I. Blake sole-stitching machine.

industrial disease have been brought to my notice lately as occurring in London'. These workers were employed on fur pulling, and the report quotes a medical registrar at St. Bartholomew's Hospital, London that, although there had been only one such case among the in-patients (the period was not stated), 'different results would probably be shown by records of out-patients'. The use of nitrate of mercury in preparing fur had been introduced into this country from Frankfurt about 30 years previously (Anderson, I898b). At the same time the newly appointed Medical Inspector went to visit a patient (a scientific instrument maker) suffering from this condition in the Holborn Infirmary, London and was told by him that there were five others badly affected. Legge (1898a) concludes, 'seeing that it is generally supposed that mercurial poisoning is a thing of the past, $I$ think a case for an enquiry into the subject has been made out'. The following month the Chief Inspector called for returns on the use of mercury from all factory inspectors (Circular, 1898). Commenting on these returns in December I898, the Principal Lady Inspector wrote to the Chief Inspector (Anderson, 1898b): 'You pointed out in your letter to me of September 2 Ist that there appeared to be no reason why section $2^{1}$ (of the Act) of 1895 should not be extended to cover cases of mercurial poisoning, and I think these reports supply evidence of good grounds for making such an extension.' The Medical Inspector, commenting on the same reports, considered (Legge, $1898 \mathrm{~b}$ ) that mercury was more widely used than would appear from the replies, and he went on to cite as a potential source of poisoning the use of mercury vacuum pumps in the manufacture of incandescent lamps. He added that several cases of chronic mercury poisoning had been reported from similar works abroad, in Berlin and Budapest. (Again, this is a case of coming

1(I) Every medical practitioner attending on or called in to visit a patient whom he believes to be suffering from lead, phosphorus, or arsenical poisoning, or anthrax, contracted in any factory or workshop, shall (unless the notice required by this section has been previously sent) send to the Chief Inspector of Factories at the Home Office, London, a notice stating the name and full postal address of the patient and the disease from which in the opinion of the medical practitioner the patient is suffering. . . .

(4) The Secretary of State may by order made in accordance with section sixty-five of the principal Act apply the provisions of this section to any other disease occurring in a factory or workshop, and thereupon this section and the provisions referred to therein shall apply accordingly. 


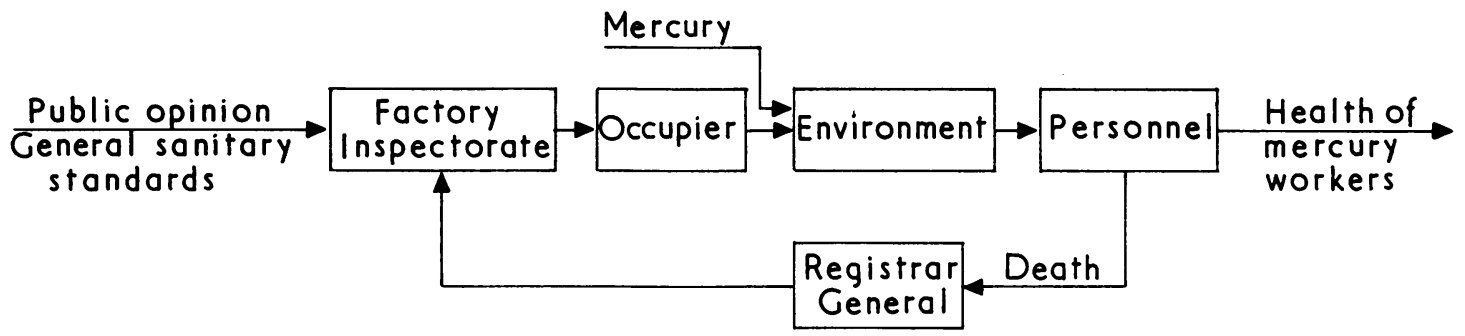

FIG. 2. Earliest control system, 1898-9.

events casting their shadows before them, for although vacuum pumps have only given rise to a few cases, three occurred in 1957 (Chief Inspector's Report, 1958), of whom one died three years later (Chief Inspector's Report, I96I)). Legge concluded his comments: 'The extension of section 29 (of the Factory and Workshop Act of 1895) to include mercurial poisoning is clearly indicated and it will probably bring to light other occupations not already known in which mercury is used', an opinion which was soon justified by subsequent events (Legge, I90I).

The comment of a senior civil servant when minuting the above reports to the Secretary of State (Minute, 1899) reveals that the matter was seen in perspective in the Home Office: 'These reports, though not disclosing a state of things that can be called serious, make out a clear case for keeping a watch on industries where mercury is used, and requiring cases of poisoning to be notified. To judge by these reports mercurial poisoning is more common than arsenical poisoning which is already notifiable.' In fact, the medical inspector, in his annual report for 1898 (Chief Inspector's Report, 1899) acknowledged that the industrial uses of mercury showed a need for supervision, although the number of persons working was small and decreasing. So on May I, I899, the order came into effect making mercurial poisoning a notifiable disease under the Factories Act (Whitelegge, 1899), and the control system was thus modified to that shown in Figure 3.

Quite soon there were some indications of the extent of the problem. Legge, in 1902, estimated that probably not more than 500 to $I, 000$ persons were exposed to the danger of mercury poisoning in Great Britain. He pointed out that the great source of mercurial poisoning for over a hundred years-the silvering of mirrors-had stopped some 20 years previously. Porter (1902) circularized all the medical practitioners in Stockport, a centre of the felt hat trade, and found that only two or three slight cases of mercurialism had been noticed in many years. He estimated that there were about 4,000 hatters in Stockport. (Not all, of course, were exposed to mercury.)

After some ro years' experience of notification, the British Medical Association, at its 67th Annual Meeting in Sheffield in 1908, held a discussion on 'The Notification of Industrial Disease'. It was generally accepted that the main object was prevention, with the added advantage of early removal of cases and early treatment (Scott, I908). Acknowledging that not all the cases were notified, Legge (I908) considered that those which were formed a good sample and were sufficient to arouse and direct attention. Reading the account of these proceedings, one is struck by the failure of some of the contributors to distinguish between the purposes underlying the notification and the scheduling

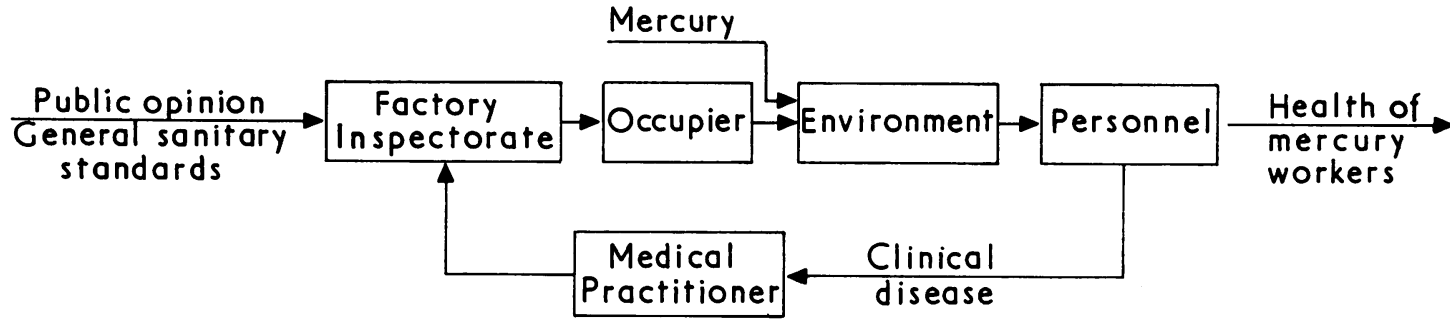

FIG. 3. Control system, 1899 to the present day. 
(known since 1946 as prescription) of industrial disease which had been introduced only two years previously in the Workmen's Compensation Act of 1906.

\section{Standards for Notification}

Before considering the numerical results of notification, it is important to examine the standards set for accepting a case as notifiable and to see whether and to what degree they may have changed with the passing of time.

The legal requirement is for notification of any case of mercurial poisoning. At first this was interpreted as fairly gross poisoning, for, in his evidence recorded in the Report of the Departmental Committee on Workmen's Compensation (I904), Legge admitted that the number of cases was small but went on: 'Yes, but they give no idea of the amount of mercurial poisoning. If I go into a thermometer workshop and examine all the hands, I will find from 30 to $40 \%$ of the men showing slight signs of mercurial poisoning.' He was next asked, 'But that is not sufficiently serious to be reported ?', to which he replied simply, 'That is so'. Nevertheless, in the Report for I90I of the Chief Inspector of Factories, it is remarked that, out of the four cases notified from hatters' furriers, three came to light during voluntary routine monthly medical inspection by a medical practitioner. 'They were thus, at the time they were reported, not incapacitated from work.' Therefore it can be concluded that at the beginning of this century the standard for acceptance for notification was definite signs of mercurial poisoning without the condition being necessarily severe enough to result in absence from work. This is very much the view repeated in the Chief Inspector's Report for 1905. Thirty years later the Report of the Chief Inspector of Factories (1936) implies the same standard. In that year only one notified case was reported, a vermillion worker, but in the same report is the comment: 'Of twenty workers examined who were exposed to mercury in the course of electric meter making, four were found to be showing signs of mild mercurialism.' Yet these apparently were not included among the notified cases. In 1959 two cases were notified. Both had symptoms and one had $530 \mu \mathrm{g}$. of mercury in a $24-\mathrm{hr}$. urine specimen. A further case of a woman handling organic mercury compounds had been reported to the Factory Department in that year, as she had a mercury in urine concentration of $\mathrm{I}, 300 \mu \mathrm{g}$. per litre, but this notification was not accepted as she had no symptoms. Thus the standard of accentance for a case of mercury poisoning remained the same as it had been over half a century earlier.

In more recent years, the emphasis has gradually shifted to diagnosis based on mild symptoms accompanied by clear evidence from mercury in urine estimations. In 1962 the Chief Inspector commented, 'Nevertheless, reports ... have, on occasion, suggested that there might be a considerable amount of poisoning at a stage where the clinical findings are rather indefinite and largely subjective. ... The recorded incidence of mercury poisoning, therefore, tends to represent only the more definite cases, where the diagnosis is seldom in doubt and the patient's condition is serious.' The following year (Chief Inspector's Report for 1963) there were three accepted cases of mercurial poisoning, two of whom had high levels of mercury in urine and mild symptoms (other persons investigated and found to have high excretion rates but no clinical evidence 'were considered to be excreting excessive amounts of mercury'). The third had slight persistent proteinuria with coincident gain in weight, which was regarded to be evidence of the threatened development of mercurial nephritis. By I964 this change in attitude to the definition of 'mercurial poisoning' had become clear. In the Chief Inspector's Report for that year it is stated that in the past 'the appearance of proteinuria and the development of oedema tended to be regarded as a manifestation of acute mercurial poisoning from soluble salts of mercury, or as a late manifestation of chronic poisoning. There is increasing doubt whether this is always the case. Four of the six accepted cases of mercury poisoning in 1964 had albuminuria and varying degrees of water retention, as previously described. Commonly the detection of albuminuria in the course of a routine medical examination, or even the sudden appearance of oedema, is the first sign in an otherwise asymptomatic worker. The amount of mercury found in the urine in such cases is not necessarily high'.

It will be seen that over the years the criteria for acceptance for a notified case have remained substantially the same-that there should be clinical evidence of mercurial poisoning. Nevertheless, there has been a move in recent years away from the former position, that more than slight signs were required, toward the view that a high mercury excretion rate, if accompanied by even slight symptoms or signs (including proteinuria), would justify acceptance as a notified case.

\section{Trends in Notified Cases}

The table shows the average numbers of cases of 
56

W. R. Lee

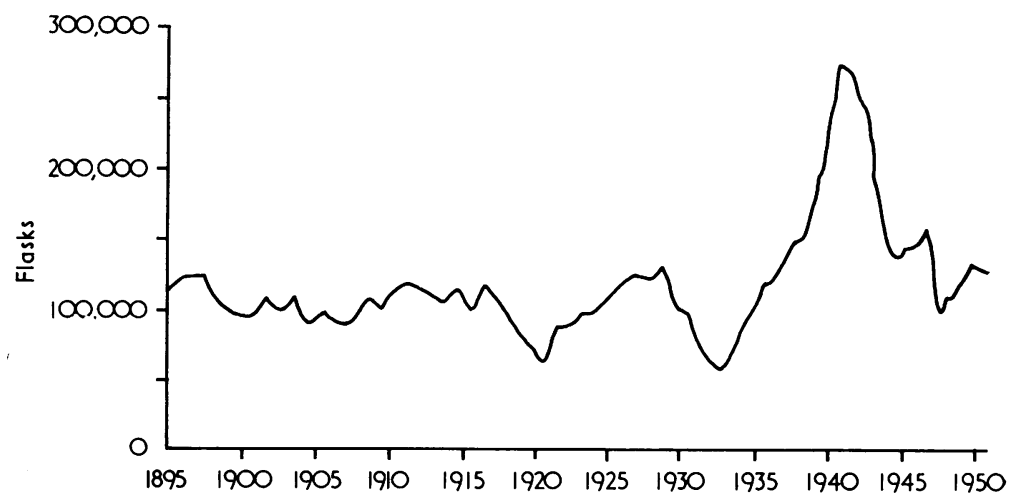

FIG. 4. World production of mercury, I 895 to I95I (Lawrence, I952).
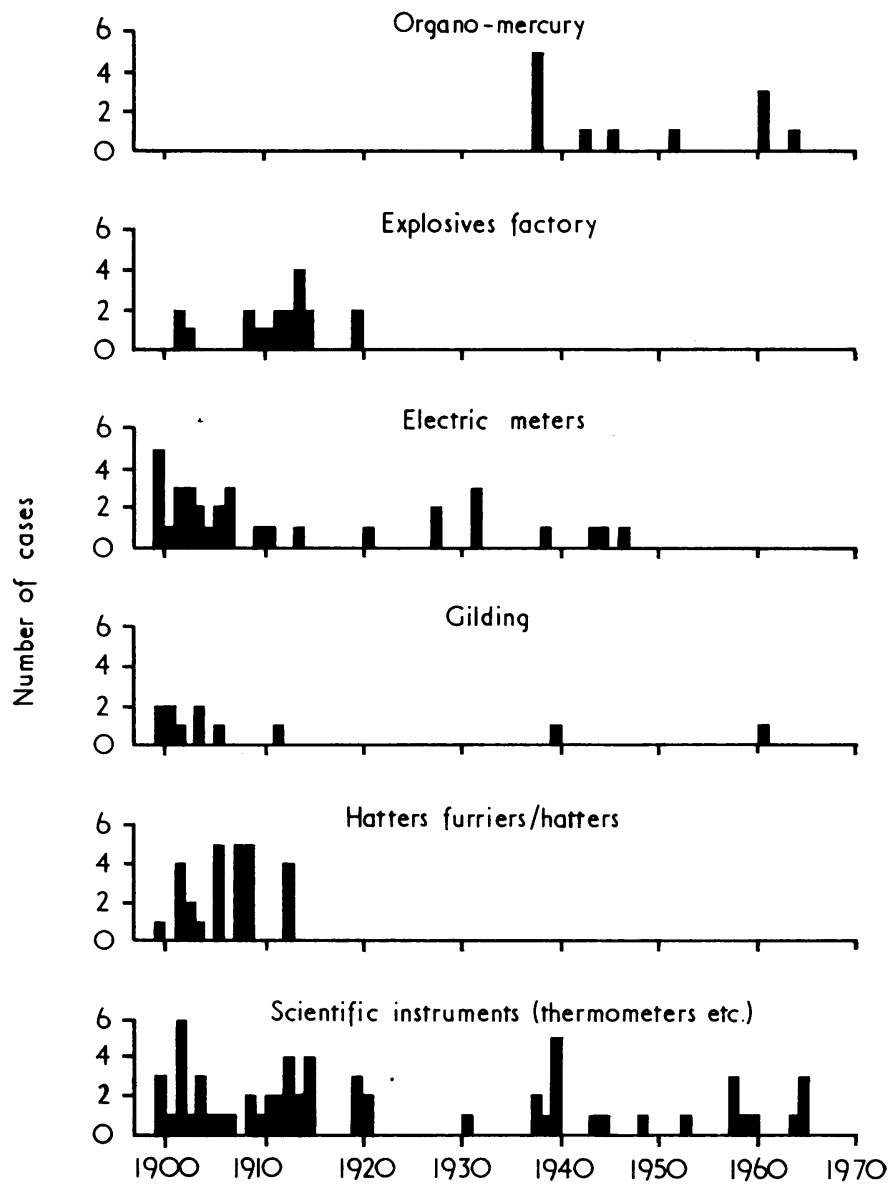

FIG. 5. Industrial mercury poisoning (notified cases), 1900 to 1966.

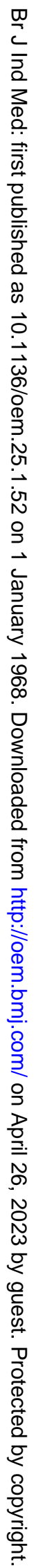


TABLE

Average Number of Cases of Disease Notified ANNUALLY

\begin{tabular}{l|r|r|r|c|c}
\hline Decade & Mercury & Lead & Anthrax & Arsenic & Phosphorus \\
\hline 1900-9 & $8 \cdot 4$ & $676 \cdot 2$ & $49 \cdot 8$ & $9 \cdot 1$ & $1 \cdot 7$ \\
$1910-19$ & $12 \cdot 0$ & $413 \cdot 8$ & $66 \cdot 3$ & $7 \cdot 0$ & $1 \cdot 2$ \\
$1920-29$ & $3 \cdot 6$ & $302 \cdot 7$ & $40 \cdot 6$ & $2 \cdot 8$ & 0 \\
$1930-39$ & $3 \cdot 2$ & $165 \cdot 8$ & $26 \cdot 4$ & $2 \cdot 3$ & 0 \\
$1940-49$ & $3 \cdot 1$ & $57 \cdot 8$ & $18 \cdot 8$ & $1 \cdot 4$ & 0.4 \\
$1950-59$ & $3 \cdot 7$ & $56 \cdot 2$ & $19 \cdot 4$ & $0 \cdot 9$ & $1 \cdot 4$ \\
$1960-64$ & $4 \cdot 2$ & $81 \cdot 4$ & $9 \cdot 6$ & $1 \cdot 0$ & $0 \cdot 2$ \\
\hline
\end{tabular}

the disease notified annually, but, when reading it, the easing in the standard which appears to have taken place in the last few years should be borne in mind. The numbers of accepted cases of other diseases also notifiable over the whole period are shown for comparison. These figures show that the incidence of mercurial poisoning has been at its present low level for over 40 years and that the recent increase in the past five or six years could be attributed, in part at least, to a change in the standard of diagnosis. In the absence of information on the numbers of persons exposed, or even on the quantity of mercury used in this country, it is not possible to deduce whether control of the disease is becoming more or less effective. The world production of mercury during this period is illustrated in Figure 4 (Lawrence, 1952).

The figures also show that, although the overall incidence of cases was high in the early part of the century and since then has remained more or less constant, the incidence in different industries has been changing (Fig. 5). When mercurial poisoning was first made notifiable, the factory department regarded the two industries principally at risk as hatters' furriers and the making of scientific instruments (or 'philosophical instrument makers', in the quaint language of those times). The preliminary survey made before the regulations were drawn up was largely confined to these two trades (Anderson, I898b; Circular, I898). In a memorandum to the Chief Inspector, Legge (I898b) considered that mercury was more widely used than would appear from the survey. This soon proved to be the case. The regulations came into effect on May I, 1899, and in that year half of the ro notified cases were from one factory concerned with the manufacture and adjustment of electric meters (this process was not among the 'philosophical instruments' included earlier). In one such factory, a system of voluntary medical examinations of the workers by the certifying surgeon was introduced.

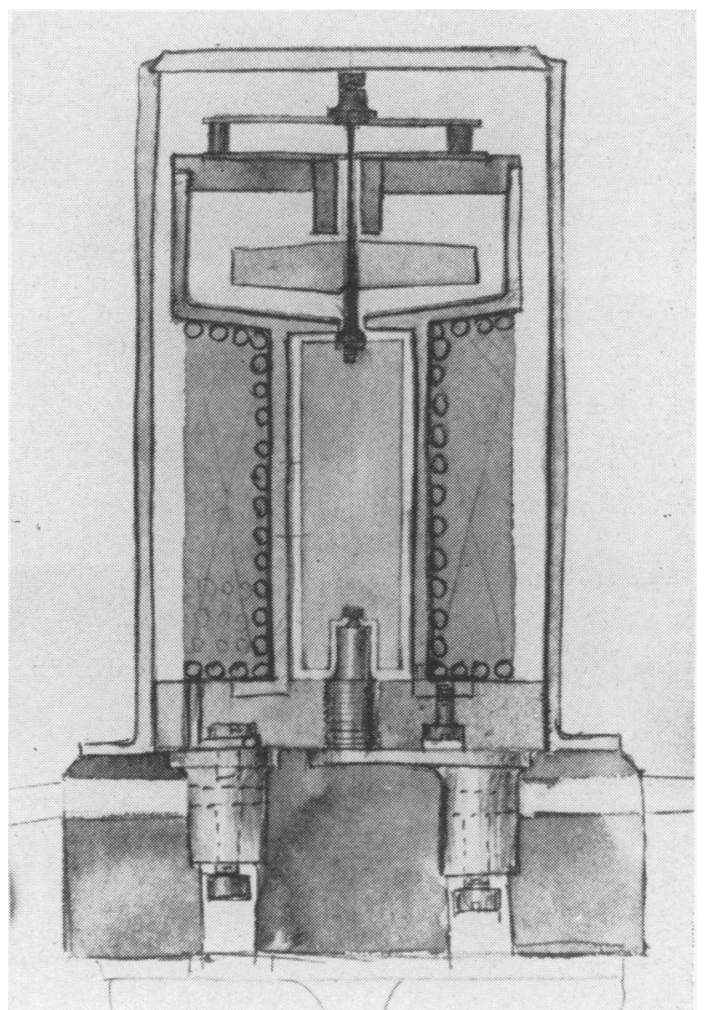

Fig. 6. Sectional drawing, made by Dr. Ferranti in 1884, showing the D.C. mercury motor meter which he invented.

One of the difficulties was described by the certifying surgeon in Brighton: ' $\mathrm{He}$ (the patient) was advised to give up his work for a month previous to his notification but did not do so for a fortnight' (Walker, 1905). It is perhaps pertinent to observe that it was not until 1906 that mercurial poisoning (along with five other industrial diseases) was included for benefit under the Workmen's Compensation Act. With modern design and changeover to alternating current, the older direct current mercury meters (Figs. 6 and 7) are now used less, and there have been only four cases reported from this trade in the past 20 years and none in the past I3 years.

In addition to hatters' furriers it was soon found that workers in subsequent parts of the trade (hatters) were also liable to the disease (Chief Inspector's Report, 1908; Tylecote, 1912). This provoked a somewhat whimsical leading article in the Lancet (I912), which concluded:

'The question may also be considered as to whether the finished material may not be a source 




Fig. 7. Mercury cleaning (at back) and magnet finishing room, c. 1917.

of danger to those who wear the felt hat, a class that obviously forms a big proportion of the community. According to an analysis of materials a "hat body" may contain as much as $0.138 \%$ of mercury. The amount of mercury in the hat would be, roughly, I part per 800 , or I oz. mercury in 400 hats each weighing $2 \mathrm{oz}$. In addition to this, arsenic was also found. We hasten to add that we are not suggesting a cause of baldness.'

Cases continued to occur among hatters' furriers and hatters until the end of the First World War. In 1919, at an International Labour Organization conference, it was reported that French workers had shown the use of nitrate of mercury in the process of carrotting rabbit fur to be unnecessary (in fact, the question of prohibiting the use of mercury in hatters' furriers processes was raised but apparently not taken further) (Chief Inspector's Report, I920). In 1935 the Chief Inspector of Factories recorded:
'One case of chronic mercurialism ${ }^{1}$ was detected in a man who had been engaged for some years in the carrotting of furs and handling a mercurial carrotting fluid under very unsatisfactory conditions. Enquiry extended to other workers where carrotting is performed made it clear that mercury as a carrotting agent is being abandoned by the more progressive firms.'

About this period a survey of 529 hatters' fur cutters in the United States (Neal and Jones, 1937) showed 43 to be suffering from chronic mercurialism; 33 were classified as mild, six as moderate, and four as severe. A similar survey of 534 hatters, again in the United States (Neal, Flinn, Edwards,

1This patient with 'chronic mercurialism' was apparently not accepted as a case of 'mercurial poisoning' for only one case of the latter (a vermillion worker) was accepted as notified in 1935 . 
Reinhart, Hough, Dallavalle, Goldman, and Armstrong, 194I), revealed 59 cases of chronic mercurialism.

But no cases from this trade have been notified in Great Britain in the last 45 years, although mercury continues to be used in the carrotting fluid (Barr, 1966, personal communication). This is the more interesting when it is recalled that a very large number of hatters' furriers, in the Manchester area anyway, work in quite small firms having only a few employees.

An ancient craft and a classical source of mercurial poisoning is gilding, which was well described by Mr. Duckering in the Report for 1912 of the Chief Inspector of Factories:

"The articles to be gilded are painted or shaken with "quick", i.e., mercury and nitric acid (or mercury nitrate). They are then placed in a receptacle with a weighed quantity of an amalgam of gold and mercury and either shaken or stirred till all the amalgam has been taken up, when they are heated over a coke or gas fire till all the mercury has been driven off as vapour.'

In the first six years of notification there were seven cases from this process and a further five cases up to the end of the First World War. But in the past 45 years there have been only two sporadic cases, the last as recently as 1960 .

As the old sources of mercury poisoning have died out or been brought under control, new ones have appeared and the annual total remains about the same. The first indication of one of these was in 1936, when the Chief Inspector of Factories recorded that 'attention was drawn to a small factory where one man handling a mercurial preparation in the process of seed dressing showed symptoms of mild mercurialism, due to lack of dust control'. The next year (Chief Inspector's Report for 1937) five cases from the manufacture of mercurial seed dressings were notified. Since that time there have been only sporadic cases, the latest being in 1963 when the only manifestations of poisoning were slightly persistent proteinuria and a coincident increase in weight.

\section{Medical Surveillance}

From the outset, Legge recommended medical surveillance of workers handling mercury (Chief Inspector's Report, I90I; Legge, I90I). Quite early he reported on three notified cases who 'came to light during routine monthly inspection by a medical practitioner' (Chief Inspector's Report, 1902). But there were difficulties from both sides of industry. Taylor (190I), of Guy's Hospital, invest- igating cases of poisoning among hatters' furriers, found that, 'Those people I have seen who are still employed at the factory have begged me not to mention to their employer that I have seen them, as they would be instantly dismissed. Two cases not mentioned here, as soon as they found out what I had called for, refused to tell me anything.' The objections raised by the employers (quoted by Oliver, 1902) were that such routine medical examinations would $(a)$ constitute an interference with the liberty of the individual; $(b)$ incur a loss of time and therefore reduce production; and (c) lead to suspension of the worker which would result in his losing wages.

At the Annual Meeting of the British Medical Association in 1902, Sir Thomas Oliver (1902) supported Legge's proposals for medical surveillance. He dealt with the first objection of the employers by an interesting argument. That objection implied the principle of volenti non fit injuria: because some men elect to go into coal mining, which they know is dangerous, why should not some men choose to work with materials which they know to be hazardous ? But, argued Oliver, the hazards in coal mining are accident and explosion, consequently preventive measures are applied to the environment, but in factories with a hazard of poisoning the law should deal with the dangers by inspecting the workers. This argument was stronger at the beginning of the century than at the present time when more sophisticated means are available for assessing and controlling the toxic environment.

Nevertheless, these arguments by the employers and the workpeople had not been sufficient to prevent the introduction of compulsory medical examination for certain lead workers at the turn of the century, when over a thousand cases of lead poisoning, with 30 to 40 deaths, were notified annually. Mercury, with eight cases a year and no deaths in the first ro years of notification, was apparently not a sufficient hazard to warrant the introduction of compulsory medical examination. And so, to the present day, the factory inspectorate has relied largely on control of housekeeping under the general provisions of the Factories Act, supplemented by the encouragement of voluntary medical examinations.

\section{The Development of Measurement}

Notification has kept attention on the continuing hazard of mercurial poisoning in industry from sources both old and new. In the investigations by the medical inspectors we can follow the evolution 
of the techniques of measurement. The first environmental investigation, reported by the Chief Inspector of Factories in 1920, was of the atmosphere of workrooms where clinical thermometers were manufactured. It was argued that, on the assumptions that $30.5 \mathrm{cu}$. in. of air were inhaled at each inspiration and that 275 days of eight and a half hours each were worked (this supposed a five and a half-day or 48-hour working week), then $18.5 \mathrm{gr}$. of mercury would be inhaled yearly. This is equivalent to an atmospheric concentration of about IOO $\mu \mathrm{g} . / \mathrm{m}^{3}$. Incidentally, this figure indicates the success of the preventive measures, when properly applied, of nearly half a century ago. A few years later (Chief Inspector's Report for 1926), there is the first reference to a measured amount of mercury in the tissues of a fatal case, but with a rather atypical clinical picture. This patient was employed in repairing electric meters, using metallic mercury. Following a two-month history of malaise and difficulty in walking, there was an acute terminal respiratory illness of eight days. Necropsy showed acute myelitis with terminal bronchopneumonia. 'Certain of the organs' had mercury equivalent to $0.38 \mathrm{gr} . / \mathrm{lb}$. This corresponds to 55 parts per million and may be compared with the findings of Brigatti (1949) of 21 and 28 p.p.m. in the kidneys and liver respectively in a worker exposed to metallic mercury vapour.

But in the r920s the idea of relating an environmental measurement to an epidemiological study of the health of the workers was hardly developed. Some 15 years previously, Boycott and Haldane (1903, 1904) and Boycott (1904), studying ankylostomiasis in Cornish tin miners, had demonstrated how the working group could be used to monitor working conditions, but a further Io years was to elapse before Lane (I93I) was to couple this technique with the measurement of the working environment and develop the concept of relating a measured environment to measured changes in the workers.

A survey by the factory inspectorate in 1962 (Chief Inspector's Report, 1963) showed that 'environmental and biochemical examinations have indicated that in many establishments using mercury and its compounds, conditions are unsatisfactory'. Out of 136 workers exposed to mercury, 39 had more than $300 \mu \mathrm{g}$./litre (of whom 26 were from an electro-chemical factory) and only one was considered to be a notifiable case, for he had mild symptoms in addition to a high excretion rate $(3,500 \mu \mathrm{g} . / 1$.$) . A further 134$ specimens were examined from workers handling organo-mercury compounds, but 'no findings suggestive of mercury poisoning were found in any of the seed dressers examined' (Chief Inspector's Report for 1963).

\section{Recent Developments}

Another idea which nowadays is sometimes taken for granted is the idea of general statutory control of a hazardous material. Since the end of the last century special preventive measures have been applied to those industries where hazards to health have been recognized to occur. But since the Second World War increasing attention has been paid to regulations directed towards a hazardous material irrespective of the industry where the material is used. Steadily, this concept is being extended, and, considering the careful and conservative approach of many government departments, coupled with the continued relatively low incidence of overt mercury poisoning, it is not surprising that it is only recently that attention has been directed at mercury as a hazardous material rather than at certain well-known mercury-using industries.

In 1963, the draft of 'Mercury Processes Regulations' was issued. More than 60 years after Legge had first advocated routine medical examinations new draft regulations were proposed, making them compulsory. But events had moved too fast. Whereas clinical detection of early cases of poisoning had been the only way at the beginning of the century, by the time these draft regulations were published it was rightly observed that routine medical examination cannot in itself prevent mercury poisoning, it can only observe it (King, E., 1964, personal communication). As has been seen, more sophisticated techniques for environmental and biological monitoring have been increasingly used and indeed had been employed in the factory inspectorate's own survey (Chief Inspector's Report, 1964) which preceded the publication of these draft regulations. Nevertheless, in the absence of a generally accepted biochemical indicator of increased absorption (Goldwater, 1964), biological monitoring must still rely to a certain extent on clinical examination. Figure 8 illustrates how these proposals mocify the systems of control.

There the matter rests. Mercury poisoning has never been a large problem. The number of notified cases fell during the early years of this century and has remained steady since, with the factory department keeping a fairly constant standard of diagnosis for notification. New methods of protecting workers from the hazard will need the new techniques which have proved their value in those large industries which have already been employing them. 


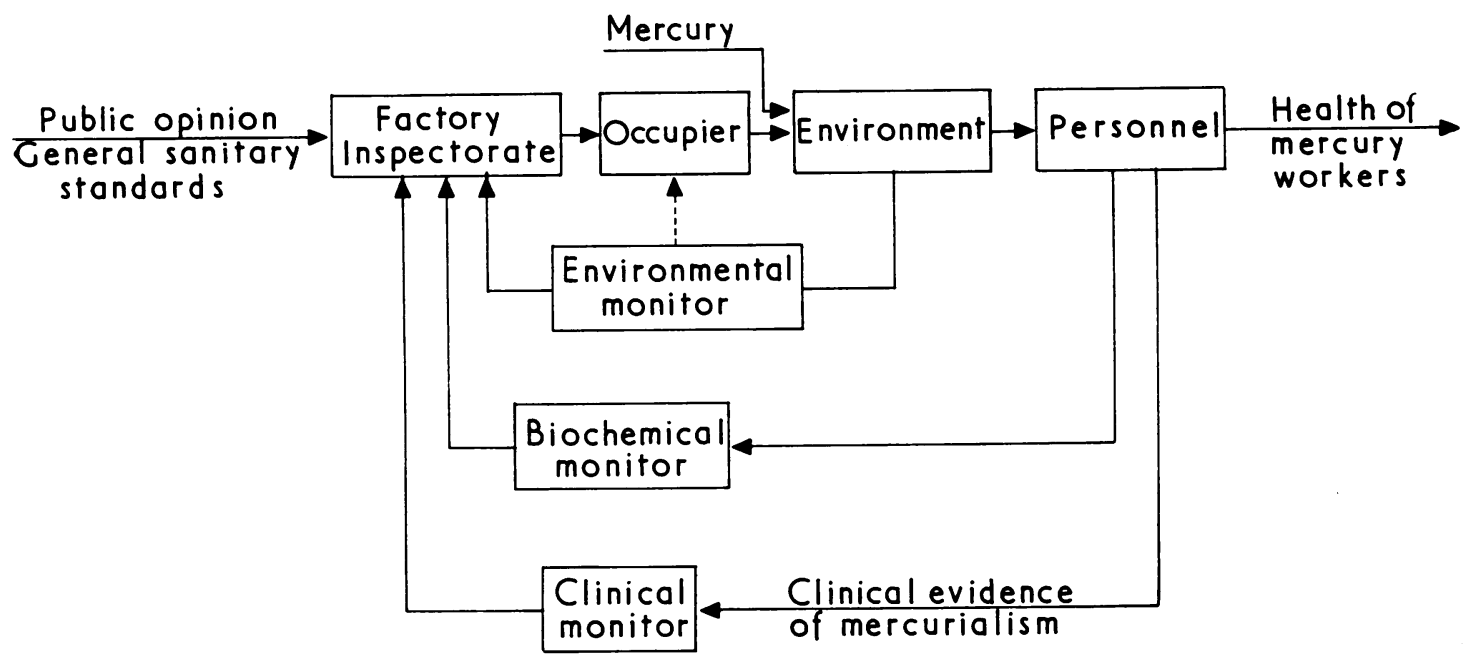

FIG. 8. Control system proposed in Draft Mercury Regulations.

\section{Conclusions-A Problem in Feedback Control}

Figures 2, 3, and 8 illustrate the stages of the development of the statutory control of mercury poisoning in the form of control loops. Such a feedback loop has two main purposes: to bring the system to a desired state of equilibrium (no deaths, no overt poisonings, minimum biochemical changes, etc.), and to hold it as stable as possible, i.e., without 'hunting' about the state of equilibrium. Several factors may influence the effectiveness of such a system.

First, the detector should be sufficiently sensitive. Clearly, information on deaths (Fig. 2) serves as a very crude sensor. Notification of illness, whether by the occupier or medical practitioner, is an obvious improvement, and sensitivity has been increased slightly further by the modification of the criteria needed for notification. Nevertheless, to use clinically detected departure from health should, according to present-day standards, be avoided where possible, and this argument applies equally to routine clinical medical surveillance. The aim is to detect deviations from the equilibrium state by environmental measurements and by personal monitoring, such as biochemical estimations, when these techniques are satisfactorily validated.

Secondly, if an 'error' occurs and the system moves away from the equilibrium state the negative feedback should operate to return the conditions as rapidly as possible. That is, there should be minimum delay in the control loop. Obviously, if it is necessary for information to be passed from the Registrar General to the headquarters of a factory inspectorate, the 'error' might increase considerably before corrective action is taken. To a lesser extent, the development of clinical poisoning, its diagnosis, and the subsequent implementation of statutory notification result in unacceptable delays. Local supervision of the environment, and perhaps of the workers also, provides a more immediate feedback of information. It must be borne in mind, however, that too rapid a feedback can have its drawbacks and may lead to 'hunting', particularly if overcorrection is applied. This implies that local control measures should be in the hands of trained and experienced persons (doctors or occupational hygienists) who work to principles and guide lines rather than follow uncritically some arbitrary maximum allowable concentration, whether in the urine or the atmosphere.

Thirdly, the regulator is action by the occupier of the factory, prompted usually by the factory inspectorate. 'Notification must be considered in relation to powers of investigation' (Williams, 1960). The statement of this proposition suggests examination of the powers of investigation and implies alsn consideration of success of the regulator. The table in the earlier part of this paper amply illustrates the effectiveness of the regulator in the past, although the recent increases in numbers of lead and mercury poisonings suggest that the feedback loop shows evidence of 'drift' as the detector has become more sensitive. Control (operation of the regulator) has not matched the increased sensitivity of detection. 
I wish to thank Dr. A. R. Cownie, of the University of Salford, for advice on the preparation of the control diagrams, Figures 2, 3, and 8.

The illustration of the Blake sole-stitching machine was taken by the Central Library, Manchester, from the Report of the Home Office Dangerous Trades Committee and is reproduced with permission of Her Majesty's Stationery Office. Figures 6 and 7 were kindly supplied by Ferranti Ltd. Figure 5 was prepared by the Department of Medical Illustration of the Manchester Royal Infirmary.

\section{REFERENCES}

Anderson, A. M. (1898a). Letter dated September 29, 1898, from Miss Anderson to Dr. Whitelegge. Home Office Registered Papers, H.O. 45/994I/B.28798. Public Record Office, London.

- (1898b). Letter dated December 19, 1898, from Miss Anderson to Dr. Whitelegge enclosing report from Miss Deane and Miss Squire. Home Office Registered Papers, H.O. 45/994I/B.28798. Public Record Office, London.

Boycott, A. E. (1904). Further observations on the diagnosis of Ankylostoma infection with special reference to the examination of the blood. F. Hyg. (Lond.), 4, 437-479.

- , and Haldane, J. S. (1903). An outbreak of ankylostomiasis in England. No. I. Ibid., 3, 95-136.

$\longrightarrow$, and - (1904). 'Ankylostomiasis' No. II. Ibid., 4, 73-III.

Brigatti, L. (I949). 'Il contenuto in mercurio degli organi di soggetti senza e con precedente absorbimento mercuriale.' Med. d. Lavoro, 40, 233-239.

Circular (1898). Circular I.99 to all H.M. Inspectors of Factories from Dr. Whitelegge. Home Office Registered Papers, H.O. 45/994I/B.28798. Public Record Office, London.

Chief Inspector's Report. (1880). Annual Report of the Chief Inspector of Factories and Workshops for the year I879, p. 37. H.M.S.O., London.

(1898). Ibid., I897, p. 63.

(1899). Ibid., I898, Part II.-Reports p. 132.

(1901). Ibid., 1900, p. I15.

- (1902). Ibid., 1901, p. 235.

- (1906). Ibid., 1905, p. 414.

(1908). Ibid., 1907, p. 241.

(1913). Ibid., 1912, p. 41.

(1920). Ibid., 1919, p. 62.

- (1921). Ibid., 1920, p. 122.

- (1927). Ibid., 1926, p. 86.

(1936). Ibid., 1935, p. 46.

- (1937). Ibid., 1936, p. 45 .

(1938). Annual Report of the Chief Inspector of Factories for the year 1937, p. 56 .

(1958). Annual Report of the Chief Inspector of Factories on Industrial Health for the year 1957, p. 24. (1960). Ibid., 1959, p. 23.

(196I). Ibid., 1960, p. 24.

(1963). Ibid., 1962, p. 10.

(1964). Ibid., 1963, pp. 19 and 29.

(1965). Ibid., 1964, p. 28.

Home Office Dangerous Trades Committee. (1898). Third Interim Report, p. 15. H.M.S.O., London.

Factory \& Workshop Act (1878). 4I Vict. Chap. 16, sect. 38. (1891). 54 \& 55 Vict. Chap. 75, sect. 8.
- (1895). 58 \& 59 Vict. Chap. 37, sect. 29.

Goldwater, L. J. (1964). The Harben Lectures 1964. Occupational exposure to mercury. Lecture I. Historical background. f. Roy. Inst. publ. Hlth, 27, 279-85.

Lancet. (I912). Mercury in the 'bowler' (Annotation). 2, $1166-1167$.

Lane, R. E. (1931). The role of punctate basophilia in the control of industrial plumbism. F. industr. Hyg., 13, 276-284.

Lawrence, J. B. (1952). A century of the mercury market. Purchasing, 33, 97-100.

Legge, T. M. (I898a). Letter dated October Io, 1898 from Dr. Legge to Mr. Gould (H.M. Sup. Insp. of Factories). Home Office Registered Papers, H.O. 45/994I/B.28798. Public Record Office, London.

- (1898b). Undated memorandum (stamped as received on January 2, 1899) from Dr. Legge to Dr. Whitelegge. Home Office Registered Papers, H.O. 45/994I/ B.28798. Public Record Office, London.

(1901). A discussion on the diseases of occupations. Brit. med. F., 2, 401-5.

- (1902). In Dangerous Trades. Ed. Oliver T., p. 434 John Murray, London.

- (1908). The notification of industrial diseases. Brit. med. F., 2, 490 .

Minute (1899). Minute dated January 6, I899, from 'K.D.' (? Sir Kenelm Digby, Under Secretary of State) to Secretary of State. Home Office Registered Papers, H.O. 45/994I / B.28798. Public Record Office, London.

Neal, P. A., and Jones, R. R. (1937). A Study of Chronic Mercurialism in the Hatters' Fur-cutting Industry. U.S. Public Health Bulletin, No. 234. Government Printing Office, Washington.

—, Flinn, R. H., Edwards, T. I., Reinhart, W. H., Hough, J. W., Dallavalle, J. M., Goldman, F. H., and Armstrong, D. W. (I94I). Mercurialism and its Control in the Felt-hat Industry. U.S. Public Health Bulletin, No. 263. Government Printing Office, Washington.

Oliver, Sir T. (1902). A discussion on the value of systematic examination of workers in dangerous trades. Brit. med. F., 2, 745-7.

Porter, C. (1902). Felt hat making: its processes and hygiene. Ibid., $1,377-381$.

Report of Departmental Committee on Workmen's Compensation (1904). Minutes of Evidence Cd. 2334. H.M.S.O., London.

Scott, A. (1908). The notification of industrial diseases. Brit. med. F., 2, 488-89.

Taylor, J. G. (I90I). Chronic mercurial poisoning, with special reference to the danger in hatters' furriers' manufactories. Guy's Hosp. Rep., 55, I7I-190.

Tillyard, Sir F. (1948). The Worker and The State. 3rd ed., p. 2 10. Routledge, London.

Tylecote, F. E. (I912). Industrial mercurial poisoning as seen in felt-hat makers. Lancet, 2, $1137-40$.

Walker, H. J. (1905). Industrial mercury poisoning: with notes of two cases. Lancet, 2, 823-4.

Whitelegge, A. (1899). Note, dated March 23, 1899, from Dr. Whitelegge to Under Secretary of State. Home Office Registered Papers, H.O. 45/994I/B.28798. Public Record Office, London.

Williams, J. L. (1960). Accidents and Ill-health at Work. Staples Press, London.

Workmen's Compensation Act (1906). 6 Edward VII chap. 58, sect. 8, Third Schedule. 